\title{
Challenges to Comparative Oral Histories of Cinema Audiences
}

\begin{abstract}
This article reflects on the challenges of comparative oral history analysis by taking the BA/Leverhulme-funded project Mapping European Cinema: a comparative project on cinema-going experiences in the 1950s (2016-2017) as a case study. The aim of MEC was to test new methodologies in order to explore and compare programming patterns and cinema-going experiences in European cities that were similar in terms of population and film exhibition structure but substantially different in terms of film culture. MEC focused on three case studies: Bari (Italy), Leicester (United Kingdom) and Ghent (Belgium). This article uses three video interviews to reflect on the theoretical framework around comparative analysis and to discuss issues of cultural specificity. Attempts at substantial comparative analysis have proved to be a challenging task because of the difficulty of analysing different film cultures cross-nationally, the complexity of standardising data, and the lack of analytical frames that could be used to explain patterns and differences revealed during the analysis. Building on the work of cultural historians studying the reciprocal traffic of culture across borders, the article adopts a theoretical framework that addresses the complexity of working with memory across national borders and linguistic barriers and emphasizes contextualization as a defining component in cross-national comparative studies. The article argues that the national specific knowledge of individual researchers enabled the authors not to overlook local perspectives while at the same time generalising across the three national cultural contexts, identifying new perspectives, and finding a common ground that could be commensurable to ensure a systematic comparative process.
\end{abstract}

\section{Keywords}

oral history; comparative; cross-national; cinemagoing; film studies

\section{Introduction}

In the twentieth century, film was one of the most emblematic, popular and globally distributed forms of entertainment. However, films were not exploited in similar ways and neither were they viewed in 
identical circumstances. For the study of cinema as a cultural practice, historical research into the experience of cinema-going is a quintessential area of research. The corpus of data on European cinema culture is extremely heterogeneous and, until now, there has been little comparative research.

This article reflects on the challenges of comparative oral history analysis by adopting the BA/Leverhulme-funded project 'Mapping European Cinema: A Comparative Project on CinemaGoing Experiences in the 1950s' (2016-2017) as a case study (hereafter referred to as MEC). The aim of MEC was to test new methodologies to explore and compare programming patterns and cinema-going experiences in European cities that were similar in terms of population and film exhibition structure but substantially different in terms of film culture. MEC focused specifically on three case studies: Bari (Italy), Leicester (United Kingdom) and Ghent (Belgium). The project originated from previous work conducted at a national level only in three separate countries, and it intended to develop and test a comparative analysis that could potentially be applied to a wider sample of European cities. During the first phase of the project, historical data related to the film exhibition structure of Bari, Ghent and Leicester was collected. For each city, information related to the cinemas in operation, such as seating capacity, ownership, management, life span, geographical position, type of programming (permanent or seasonal) and run was gathered. In addition, programming data related to twelve months of screenings was collected for each cinema to understand the similarities and differences in film offer among the three cities. The decision to focus on 1952 was guided by our intention of analysing cinema-going experiences that related to a time in which cinema as a form of entertainment was still extremely popular in Europe. During the initial phase of data gathering, a crucial challenge was to achieve a level of data and metadata standardisation that would ensure a systematic comparative analysis of film structures and programming patterns.

The project's second phase focused on the analysis of three video interviews with participants (all women, selected for the purpose of comparativeness) living in the cities in the 1950s. The interview with Liliana (born in 1931, Bari and aged 83 at the time of the interview) was conducted in the framework of the 'Italian Cinema Audiences' project (further referred to as ICA) ${ }^{1}$; the interview with Yolande (born in 1946, Ghent, and aged 68 at the time of the interview) was done within the doctoral research 'Ghent Cinema City'. ${ }^{2}$ Both interviewees were selected for this article because of their city of residence (Bari and Ghent) in the 1950s. The last interview used is with Diana (born in 1934, Leicester, and age 82 at the time of the interview) and was added for the purpose of comparative 
research in the MEC project. The interviews were between 30 and 80 minutes long and the questions were all of a similar content. Although Liana's interview is accessible on the CineRicordi digital archive (www.cinericordi.it), the other two interviews were not made accessible because at the time there were no consent forms that addressed the concerns of the GDPR privacy law. The results of this pilot project have been presented at several international conferences. ${ }^{3}$

The final deliverable of MEC was to develop a model that could be used and expanded to include other countries. The development of a model to expand the initial data from the three countries attracted great interest from the academic community. It also provided the basis for the development of the AHRC-funded 'European Cinema Audiences. Entangled Histories \& Shared Memories' project (hereafter to as ECA) ${ }^{4}$, which focuses on seven European cities and adopts the methodology tested in the MEC pilot project. MEC was also the continuation of a research initiative that started in early 2014, funded by 'Digital Cinema Studies', ${ }^{5}$ which allowed researchers to promote a multi-institutional and international collaboration on cinema-going experience in the post-war period and test new methodological approaches to the comparative study of national film cultures.

Attempts at substantial comparative analysis of data have to date been unsuccessful because of the difficulty of analysing different film cultures cross-nationally, the complexity of standardising data, and the lack of analytical frames that can be used to explain patterns and differences revealed during the analysis. According to Biltereyst, Van Oort and Meers, the development of comparative research within film and cinema studies has been weak. ${ }^{6}$ The intention of MEC was to test comparative research into film cultures by triangulating exhibition structure data, programming data and audience interviews. Our project used Linda Hantrais' definition of cross-national and comparative study as research:

When individuals or teams set out to examine particular issues or phenomena in two or more countries with the express intention of comparing their manifestations in different sociocultural settings (institutions, customs, traditions, value systems, lifestyles, language, thought patterns), using the same research instruments either to carry out secondary analysis of national data or to conduct new empirical work. The aim may be to seek explanations for similarities and differences, to generalise from them or to gain a greater awareness and a deeper understanding of social reality in different national contexts. ${ }^{7}$ 
For the purpose of this article, we use the interviews to reflect on the theoretical framework around the comparative analysis of film cultures across three mid-sized cities and discuss issues of cultural specificity before providing some examples from the three case studies. We do not, however, discuss the complexity around the use of multiple languages in the project and the compromise of translation inherent in the oral history, which we are currently testing in the ECA research.

\section{Theoretical Framework to Comparative Histories}

Building on the work of cultural historians studying the reciprocal traffic of culture across borders, ${ }^{8}$ our research aims to move beyond the particularism of national cinema histories and language differences to explore not only shared memories of cinema-going across European cities but also compare more broadly diverse film cultures across Europe. The aim is to open up new perspectives on the relationship between the institutional contexts of film consumption and the remembered experience of cinema-going across Europe. ${ }^{9}$

Several studies agree ${ }^{10}$ on the 'complexity of working with memory across national and linguistic barriers'11 and on the preference for large-scale survey-based studies as the 'most typical approach to dealing with cross-national comparison in Europe. ${ }^{12}$ Bornat reminds us that - despite gathering contributions from several countries - even the International Yearbooks of Oral History and Life Stories do not work together on a shared project nor are they in any way comparative. ${ }^{13}$ In their Special Issue of Image [\&] Narrative, titled Audiovisual Memory and the Re-Making of Europe, Rigne and Erll, however, outline the current importance of transnational and transcultural perspectives for memory studies. ${ }^{14}$ This echoes the many calls in the Humanities and Social Sciences for the study of culture to go beyond 'methodological nationalism'. ${ }^{15}$ This is precisely the aim of our project: to move beyond such methodological nationalism and develop a truly comparative analysis on the experience of cinema-going in Europe. Already in 2005, Paul Willemen had proposed 'a number of probably inevitable theoretical frameworks and tools to implement a comparative approach to the study of a thoroughly industrialized cultural form, such as cinema and films. ${ }^{16}$ However, his approach was geared more towards the study of film image and its cultural significance through four theoretical constellations than the study of film consumption, cinema memories and practices of cinema-going, which is at the heart of our research. Much closer to the thesis of this project is Biltereyst and Meers' 'call for more systematic comparative research' ${ }^{17}$ within New Cinema History. Their article, while 
exposing the 'monocentric' approach of the NCH research available up until recently, invites scholars to develop a comparative perspective which 'would be helpful when trying to understand larger trends, factors or conditions explaining differences and similarities in cinema cultures. ${ }^{18}$ This method would entail research designs enabling 'a thoughtful, systematic comparison of cinematic phenomena across different geographic or temporal entities.' ${ }^{19}$ To a certain extent, however, large scale national projects - such as the 'Italian Cinema Audiences' or the 'Cultural Memory and British cinemagoing of the $1960 \mathrm{~s}^{20}$ - already present a comparative dimension. The distinction between the north and the south of the country, and rural and industrial areas, as well as the insular and continental divide are just some of the attributes used in these projects to explore and investigate the distinct practices of cinema-going which emerged as unequivocally unique according to the specific category used. At the same time, Biltereyst and Meers' call for something more 'systematic' ${ }^{21}$ reveals researchers' reluctance to embark on projects which are not only complex in nature but also require significant compromises beyond those of single-country studies. ${ }^{22}$ If 'researchers working on cinema history at different places’ collaborating 'using a symmetrical methodological set-up' is described as 'an ideal scenario' still 'quite rare within the humanities, ${ }^{23}$ it is this methodological approach that has been selected by our research project, with the aim of employing a clear framework that remains the same regardless of the geographical location investigated.

This choice, however, increases the number of challenges researchers are confronted with in relation to the different stages of any project: data collection, data preparation for analysis and data analysis. Taking the MEC research as an example, in terms of data collection and data preparation, the data had to undergo a very time consuming process of harmonisation as well as the creation of metadata and written 'data notes' that document the choices made in collecting and organising the data itself. ${ }^{24}$ We examine these from both a theoretical and methodological perspective and provide some examples in the following section, focusing in particular on the issue of cultural specificity.

Through an initial exploration of the oral history data, we have both paid attention to the common ground shared by interviewees from different countries, while simultaneously attempting to retain the cultural specificity across diverse cultural and geographical contexts. This is perhaps the biggest challenge of the project: to produce some 'generalisable theoretical statements that transcend specific times and places, ${ }^{25}$ while preserving the cultural particularities of the individual places under scrutiny. Similarities and differences are by no means results (as we have only examined a very limited number of oral histories across the three cities) but instead constitute a starting point for 
seeking robust explanations of what lies behind those similarities or differences, in order to gain a better understanding of how social processes operate. This must be done in what Hantrais calls a shift from 'universalistic culture-free approach to culture-boundedness, ${ }^{26}$ where contextualisation is central and 'an in-depth understanding of the socio-cultural, economic and political contexts in which social phenomena develop is a precondition for successful cross-national comparative research. ${ }^{27}$ We have therefore aimed to consider the cultural context in which those memories have been shaped. If 'greater emphasis has been placed on contextualisation' 28 as 'a major component in cross-national comparative studies, ${ }^{, 29}$ our research must interpret the oral history data within a wider context. This means interpreting it in relation to other types of data, which includes not just a broad review of the current literature, but extends as wide as the programming and box office data as well as the socio-demographic data, both at the local level of the cities under scrutiny and at national and supranational levels. As Brannen states, 'bringing in contextual data from other sources than the empirical research project can be much more than a literature review, 30 as 'empirical studies of a qualitative kind are supplemented by mapping exercises, literature reviews and secondary analysis of large-scale data sets.' By contextualising our empirical data within different national contexts, we are forced to consider vital aspects, such as linguistic and cultural factors, that cannot be ignored. ${ }^{31}$ For example, when examining Ghent, the film reception analysis must consider the multilingual reception (Flemish and French) and the significance of different audiences in different socioeconomic contexts. As this is solely specific to Ghent, the process of identifying overarching aspects might run the risk of losing the cultural specificity of local analysis. Moreover, even in the case of a shared practice, such as Catholic censorship and its intervention both in Belgium and in Italy, we must question 'whether something compared in different countries, or nations, is in fact the same, or equivalent in its significance, in different settings; whether it holds an equivalent meaning for the people, actors or participants in the different countries, embedded as they are in different cultural context. 32 This means avoiding, for example, the presupposition that going to the cinema was a free activity for all cities involved in the project, as compulsory Catholic screenings might be operating in Italy but certainly not in the UK. In an attempt to reconceptualise the way cinemagoing experience is studied, new theoretical frameworks and new methodological tools must be developed to understand how this experience emerges from different socio-historical contexts. At the same time, it remains vital to maintain 'a collaboration between intellectuals from different geo-historical formations' 33 to develop a truly successful cross-national comparative project. 


\section{Testing the process of data collection and refining the questions}

As highlighted by Biltereyst and Meers, one of the most challenging aspects of a comparative project aimed at analysing film exhibition practices in two or more countries relates to the competence and knowledge required to study a diverse range of geographical areas and their contexts. ${ }^{34}$ The literature shows that much cross-national research is undertaken collaboratively by teams or individual researchers who bring the specific knowledge required to overcome cultural and language barriers and challenges related to comparability. Reflecting back on the initial choices made during the development of our MEC project, we provide some methodological considerations below.

\section{Selecting the case studies}

The selection of the countries and the cities that became the focus of the project was dictated mainly by the researchers' expertise. Individually, we had all worked on separate projects that analysed cinema-going memories and programming data at a national and local level. Moreover, to develop a comparative model of analysis, the three cities studied in the MEC project (Bari, Ghent and Leicester) were selected because of their similarity in terms of population density. In addition, at the beginning of the 1950s the three cities had a similar number of cinemas in operation and, more generally, they were more representative of the film exhibition structure present in mid-sized cities in Italy, Belgium and the UK than their capital cities. Issues and challenges with the comparative approach emerged when the team began to analyse the data and the results of individual and national specific/local research from a cross-national perspective. As mentioned above, researchers involved in comparative work are conscious of the problem of equivalence across systems $;^{35}$ that is, whether the same type of data collected in different countries holds an equivalent meaning given the diversity of cultural and social contexts. In light of this, a brief discussion of the process we followed to adapt and finalise the questions used for the video interviews conducted in Leicester is given below.

\section{Preparing the questions}

As the crucial aim of the MEC project was to establish, develop and test a method for comparative analysis of European cinema-going memories and film exhibition data, we began considering the questions in our previous projects. The questions used for the interviews in Bari (Italy) were originally developed for the ICA project led by Daniela Treveri Gennari, and the questions for the interviews conducted in Ghent (Belgium) were designed by Lies Van de Vijver for the Ghent project. Obviously, 
both sets of questions were designed to consider the cultural and social specificities of Italian and Belgian respondents but also to tackle project specific objectives. On the one hand, ICA's project included questions related to Italian national cinema on Italian neorealism but also questions about film stars (both international and national). On the other hand, respondents in Belgium were asked more extensively about ideology, religion and language and how these affected their cinema-going habits. Although both projects included questions that were thematically similar and provided answers that could have been considered for a comparative analysis, our goal was to develop a set of questions that could be used in a cross-national research project. This was necessary to provide us with data that could be compared but also capture culturally specific aspects of our diverse groups of respondents. In other words, we required a research tool that would minimise issues of equivalence without homogenising the data, and simultaneously allow for cultural, historical, political and social aspects to surface during the interview process. The questions adopted for the interviews conducted in Leicester resulted from a reconsideration of the ones created for Bari and Ghent and were used to test the project's potential for expansion to a larger number of European cities. It is worth highlighting that the interviews conducted for MEC were intended purely to test the process of data collection in a cross-national research environment. They were not meant in any way as data for content analysis. However, the interviews nonetheless provided valuable insights which helped us refine the final questions for the ECA project, as explained in the next section.

Divided into thematic sections that overlapped with that which was asked to Italian and Belgian respondents, MEC's list of questions followed a semi-structured interview methodology which entails a more flexible and fluid process. This allowed space for discussion by using open-ended questions structured around topics and themes. The flexibility of the interview format encouraged an open conversation, which 'stimulated curiosity' and the emergence of 'unexpected themes'. ${ }^{36}$

The aim of the interviews was to gain a deeper understanding of the interviewees' story and of the meaning of cinema-going experience in the participants' lives. The first set of questions covered the context of 'when', 'where', 'with whom' and 'how' the respondent remembered visiting the cinema in the 1950s. We asked them to recollect their first and strongest memory of going to the cinema, their cinema preference and how they chose a certain venue. The following questions focused on the rituality of cinema-going, such as transport, seating, dress code, and whether this changed over the course of the period under scrutiny. A third set of questions aimed to expand further on the experience of the venue, the socially constructed image of the venue itself, how it was related to 
community life, and what cinema-going meant for each respondent. Finally, respondents were asked about the actual films and what titles, stars and genres were remembered and why.

\section{Refining the methodology: spatial analysis}

The examples below are provided from the interviews carried out with Yolande (born in 1946, Ghent), Diana (born in 1934, Leicester) and Liliana (born in 1931, Bari). This material provided us with insights on how to refine our methodology in a wider cross-national project. In particular, two areas of investigation came to the fore: the relationship between space and memory and the emotional attachment to specific films in relation to personal events in participants' lives.

All three respondents' memories are related to the experience of cinema-going in the urban environment, and they articulate, from a personal perspective, the two categories of cinema-going memories described by Kuhn: those related to the 'cinema in the world' and those related to the 'world in the cinema'. ${ }^{37}$ For instance, they all remembered the importance of their experience in the neighbourhood, the proximity of the cinemas and the safe and easy accessibility of these venues. Cinemas were, for instance, reached by foot as there were sufficient films available in their neighbourhood areas. As Yolande remembered:

It was always the same road. For the nearest cinema, this wasn't a problem. The Lido was quite far away though. If the movie finished late, around eleven o'clock, it was very quiet and dark on our way back. There weren't even streetlights! Sometimes we sang a song when walking home. Not too loud though, but sometimes we entered our house still singing.

Interestingly, Yolanda describes her walk through the neighbourhoods in a very physical way: she comments on the rituality of the journey, as well as on its lack of safety and on the measures taken to protect herself. This close relationship with the urban space is shared by the other respondents. While asking about the familiarity of the neighbourhood, they describe streets, lighting, local businesses, churches and literally point towards the correct direction of their travel. The location of the cinemas was very much entwined with memories of the urban environment, leaving us to question the importance of the road they took and the places they encountered along the way. The geographical characteristics of cinema memories as 'place memories' have already been described by scholars. ${ }^{38}$ They are evidence of a 'physicality' of the cinema-going experience, a close relationship with the local urban environment and a personal meaning imbued in the journeys they took to their favourite 


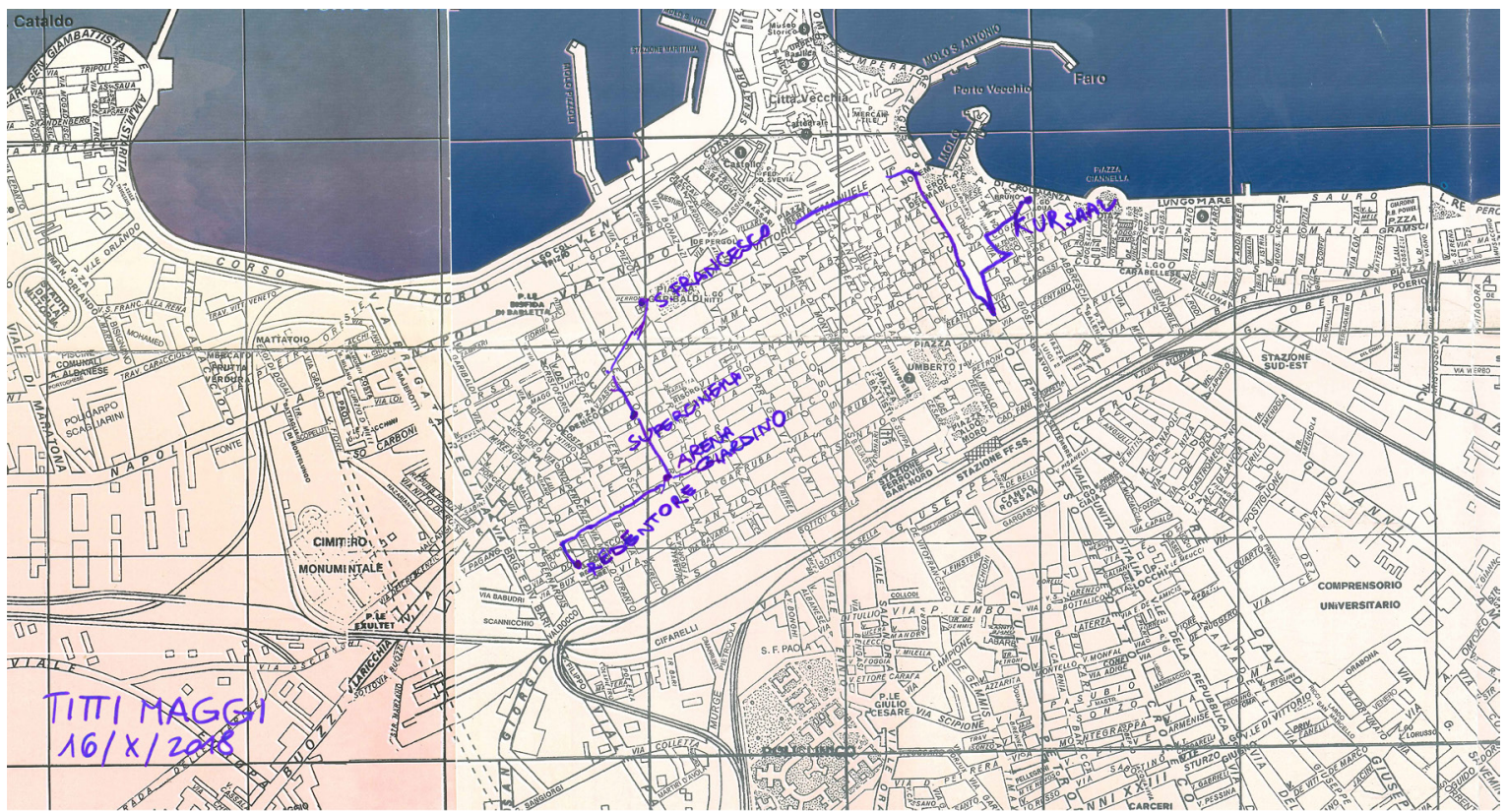

Figure 1. Titti Maggi from Bari drew her walk to the different cinemas (16 October 2018), as part of the interview for the European Cinema Audiences project (AHRC 2018-2021).

venues. This physicality reinforces the importance of a geographical dimension to cinema-going memory, one which requires a more accurate capture. In fact, in our current ECA project we decided to explore the cartographic dimension of cinema in different ways. Firstly, we included the use of a digital historical map as a tool of visual elicitation for triggering memories. This allowed us to experience the process of geographical recollection directly related to the main landmarks of the participants' urban environments. At the same time, we provided participants with printed copies of the city map so that they could physically trace - and draw - their journeys to and from the cinema (see Figure 1). This enabled us to record their 'memory walk' and therefore to map their cinema-going experience of the city and thus analyse the trajectories of all respondents. These memory walks are recorded as part of the video-interviews, while the maps are digitised for analysis.

Within these geographical considerations, it is also worth emphasising that the climatic conditions of these different regions had an impact on the location and architecture of the cinema venues, the choice and experience of the venues, and consequently of the films. As a southern coastal city, Bari had a number of open air cinemas operating during the summer months that guaranteed a wider choice while offering a different practice of cinema-going experience. Liliana, for instance, remembers going to the Arena Giardino so she could watch the film in the garden and enjoy the fresh 
air. This geographical aspect which impacts on the culturally specific dimension of her experience must be considered when compared to Yolanda and Diana's memories of cinema-going in northern Europe. Leicester and Ghent had different weather conditions which also affected their cinema choices. Diana, for instance, remembers the importance of the tram stop in front of a cinema:

Braunstone was a very big area in Leicester, and there was enough people to fill the Roxy just from that area. And then there was a tram stop outside, and a tram down into town. But it was just that bit far, and of course, you know what English weather is like, you don't want to be travelling too far and sit there in wet clothes and things.

Diana's memory is significant not only for the way in which audiences were affected by climate conditions in different geographical locations, but also the manner in which it highlights the importance of public transport, which was often a necessity for audiences wanting to travel across urban environments to reach cinemas in different neighbourhoods. Once again, this was more unavoidable in the case of Leicester and Ghent than for Bari, where the good weather allowed spectators to walk further distances to reach their favourite cinemas.

\section{Refining the methodology: film analysis}

In addition to memories' geographical dimension, the other issue raised by questioning our methodology concerns the role played by films, which are related to the participants' personal lives as well as their social and cultural contexts. As mentioned above, the set of questions used for Leicester in MEC resulted from a careful consideration of the questions used in previous projects. Those designed for the Ghent research focused more explicitly on the experiences of the cinema venue, issues related to pillarisation and censorship, and less on the actual memory of the films screened in those venues. Yolande, for instance, was not asked about the memories of certain film narratives or scenes, or the impact of technological changes, and hence her memories are mainly centred on the space of film consumption:

The nearest cinema was the Casino and the one we also visited most frequently. I didn't really have a preference, I came for the movie, not for the building, although the Lido at the Brusselsesteenweg was more modern. I can remember that there even were lights, wall lamps that shone upwards and there was a beautiful scene. The two cinemas, the Casino and the 
Agora, were probably older and not that luxurious, but the Lido was definitely the best one. In the end, the theatres didn't really matter to me, the movie did.

Yolanda, however, reminds us that films were important and more investigation was needed to understand what specifically mattered in films, why they were important and what exactly was left in audiences' memories after seeing the films. For this reason we decided to examine the questions used for the ICA project, as they allowed the respondents to elaborate on their memories of the films watched, as well as discuss the resonance of national film production to audiences' everyday life. When asked about the memories of films, Liliana remembers a profound emotional involvement in watching Italian films:

I watched beautiful films such as 'Anni difficili' by Zampa about the postwar period (...). Really beautiful Italian films with which ... there was a relationship. Yes, there was a relationship. Maybe not on a personal level, but concerning people you could see and relate to in reality.

\section{Finalising the questions}

The questions used for Leicester in the MEC project were the result of a careful re-balancing of these two approaches. The cross-national method adopted, in fact, integrates questions on the cinema venues with a variety of film-focused queries, such as questions regarding the memories of certain films or film scenes, star appeal and the emotional experiences that came with them. This added dimension to the video interview not only enables a reassessment of a corpus of texts rarely recognised in academic film histories but remembered by the audiences, but may also offer a richer narrative on the traces films leave behind on spectators after a long period of time, as well as how these traces change within different cultural settings. The MEC memories on film persuaded us to more closely examine not only the local context of viewing, but also the significance of remembering particular films, characters, national film production and specific film scenes, and how this has impacted the memory narrative of cinema-going. This is also in line with our yearning to investigate the role played by film in historical studies of cinema and its audiences. ${ }^{39}$ For instance, in her interview Diana highlights her fond memories of musicals but also of films of the late 1950s starring Elvis Presley. Both musicals and Presley’s films 'merged' into one unique experience encompassing 
her two great passions, film and music, but also combined her love of dancing with that of going to the cinema.

Our experiences with the three case studies used within MEC to test the methodology has not only strengthened our determination to work with a wider selection of respondents (in terms of class and gender) and a more varied selection of case studies (in terms of socio-political context), but they have also taught us to expand to the remembered experience of urbanity and the film medium itself. It is precisely this aim that the ECA project, which expands on the MEC pilot project, is designed to achieve.

\section{Conclusion}

If - as Bornat states - 'concern about managing contextual complexity has been a deterrent to the pursuit of cross-national comparative research, ${ }^{40}$ our research also indicates the necessity of engaging with comparative research in audience studies while simultaneously emphasising the urgency to evaluate past methodologies in light of the specific nature of the research. This contextual complexity should not deter involvement in comparative research. On the contrary, it should be embraced, especially within the context of oral history, in order to resist the recurrent monolingual and monocultural approach to oral testimonies. Going back to Hantrais' definition of cross-national and comparative study, ${ }^{41}$ we feel that explanations for 'similarities and differences' can only be sought when a truly systematic process is implemented. This means a sound methodology that highlights and considers social and cultural realities in different national contexts and calculates methods of preserving those differences in the analysis of the data. Our lengthy process of testing and enhancing each individual stage of the project has allowed us to place extra emphasis on contextualisation, interpreting the context of film consumption across diverse environments to better understand the memories of cinema-going within a multicultural project. The variety of conceptual approaches used in previous projects facilitated a refinement of our methodology and an evaluation of the significance of cultural specificities in each national dimension, while ensuring that a truly multicultural analysis was being conducted. If - as Biltereyst and Meers state 'comparison (...) is an essential part of a discipline's strategy (...) to establish a better understanding of the object under study ${ }^{42}$ - then the promotion of a multi-cultural dimension of cinema studies and cinemagoing in particular can unquestionably reveal new explanations. This can only be achieved once each 
researcher is able 'to understand the thought processes of another culture and to see it from the native's viewpoint, while also reconsidering their own country from the perspective of a skilled, external observer. ${ }^{43}$ This is especially important when considering oral history; as Alessandro Portelli argues, oral history is valuable but 'it tells us less about events as such than about their meaning (...) the unique and precious element which oral sources force upon the historian (...) is the speaker's subjectivity.'44 To capture that speaker's subjectivity, we must ensure the sense is not only understood globally but also in the context of the specific country from which it derives. The national specific knowledge of individual researchers has enabled us to avoid overlooking local perspectives while simultaneously generalising across the three national cultural contexts, identifying new perspectives. However, this can only be achieved through a series of methodological and practical adjustments made in order to address the 'paramount challenges of time and space, comparability, culture and language in the research process. ${ }^{45}$ Our main adjustment was finding a common ground that could be comparable. This has inevitably excluded some key aspects of the research from the broader picture but has, however, ensured that a systematic comparative process was implemented and that the voices of the respondents were interpreted within a cross-national research project.

\section{Notes}

1. 'Italian Cinema Audiences' is a collaborative research project exploring cinema audiences in Italy in the 1950s. It is led by Daniela Treveri Gennari (Oxford Brookes University), Catherine O’Rawe (University of Bristol) and Danielle Hipkins (University of Exeter), and funded by the Arts and Humanities Research Council (AHRC, 2013-2016). More information: www.italiancinemaaudiences.org.

2. 'Ghent Cinema City' (Gent Kinemastad) is a follow-up study of 'The Enlightened City’ project, focusing on the history of cinema culture in the city of Ghent and its suburbs (1896-2010). It was led by Daniel Biltereyst and Lies Van de Vijver (Ghent University) and funded by the Ghent University research fund (BOF, 2009-2012). More information: www.cinemacitycultures.com/ghent-cinema-city.html.

3. The results of the comparative research in MEC have been presented at several conferences and consisted of comparing film markets (ECREA, Cork, 2017), comparative programming research (f.i. ECREA 2016) and comparative oral history research (f.i. HoMER conference, Toronto, 2017) using network analysis and geo-visualisation tools. 
4. 'European Cinema Audiences' is a comparative research project that explores European film cultures in the 1950s. The project is led by Daniela Treveri Gennari (Oxford Brookes University), Lies Van de Vijver (Ghent University), and Pierluigi Ercole (De Montfort University), and is funded by the Arts \& Humanities Research Council (AHRC, 2018-2021). It stems from the British Academy / Levershulme fund in 2016. More information: www.europeancinemaaudiences.org.

5. 'Digital Cinema Studies' is a scientific research network funded by the Research Foundation Flanders (FWO, 2014-2018) led by the Centre for Cinema and Media Studies (CIMS), the Visual and Digital Cultures Research Center (ViDi) and the Institute for Media Studies. More information: www.digitalcinemastudies. com.

6. Daniel Biltereyst, Thunnis Van Oort and Philippe Meers, "Comparing Historical Cinema Cultures: Reflections on New Cinema History and Comparison with a Cross-National Case Study on Antwerp and Rotterdam," in The Routledge Companion to New Cinema History, ed. Daniel Biltereyst, Richard Matlby and Philippe Meers (London/New York: Routledge, 2019), 96-111.

7. Linda Hantrais, “Comparative Research Methods,” Social Research Update 13 (1995), http://sru.soc.surrey. ac.uk/SRU13.html, accessed 23 March 2019.

8. See Peter Burke, Varieties of Cultural History (Cambridge: Polity Press, 1997); Lilach Sagiv and Shalom H. Schwartz, “Cultural Values in Organizations: Insights for Europe,” European J. International Management 1, no. 3 (2007): 176-190; Michael Werner and Bénédicte Zimmerman, “Beyond Comparison: Histoire Croisée and the Challenge of Reflexivity," History and Theory 45, no. 1 (2006): 30-50.

9. Daniel Biltereyst, Richard Maltby and Philippe Meers eds., Cinema, Audiences and Modernity: New Perspectives on European Cinema History (London/New York: Routledge, 2012).

10. See Peter Coleman, Daniela Koleva and Joanna eds., Ageing, Ritual and Social Change: Comparing the Secular and Religious in Eastern and Western Europe (Farnham: Ashgate Publishing, 2013); Emily Keightley and Michael Pickering eds., Research Methods for Memory Studies (Edinburgh: Edinburgh University Press, 2013); Steen Mangen, “Qualitative Research Methods in Cross-National Settings," in Cross-National Research Methodology and practice, ed. Linda Hantrais and Steen Mangen (London/New York: Routledge, 2006), 19-34.

11. Joanna Bornat, "Oral History and Remembering," in Research Methods for Memory Studies, ed. Emily Keightley and Michael Pickering (Edinburgh: Edinburgh University Press, 2013), 19-43, there 19.

12. Bornat, “Oral History,” 20.

13. Ibid., 21. 
14. Ann Rigne and Astrid Erll, "Audiovisual Memory and the Re-Making of Europe.” Special Issue, Image [\&] Narrative 18, no.1 (2017).

15. Andreas Wimmer and Nina Glick Shiller, "Methodological Nationalism and Beyond: Nation-State Building, Migration and the Social Sciences," Global Networks 2, no.4 (2002): 301-334.

16. Paul Willemen, “For a Comparative Film Studies," Inter-Asia Cultural Studies 6, no.1 (2005): 98-112, there 98.

17. Daniel Biltereyst and Philippe Meers, "New Cinema History and the Comparative Mode: Reflections on Comparing Historical Cinema Cultures,” Alphaville 11 (2016): 13-32, there 13. See also Annette Kuhn, Daniel Biltereyst and Philippe Meers, "Memories of Cinemagoing and Film Experience ... An introduction,” Memory Studies, 10, no.1 (2017): 3-16.

18. Kuhn, Biltereyst and Meers, "Memories of Cinemagoing."

19. Ibid., 14-15.

20. 'Remembering 1960s British Cinema-Going' is a new project funded by the Arts \& Humanities Research Council (AHRC, 2017-2018) that aimed to make many more people aware of the research done by an earlier AHRC project, 'Cultural Memory and British Cinema-going of the 1960s' (AHRC, 2013-2015) led by Melvyn Stokes (University College London).

21. Biltereyst and Meers, “New Cinema History,” 17.

22. Linda Hantrais and Steen Mangen, Cross National Research Methods (London: Pinter, 1996).

23. Biltereyst and Meers, "New Cinema History”, 22-23.

24. Julia Noordegraaf, Kathleen Lotze and Jaap Boter, "Writing Cinema Histories with Digital Databases: The Case of Cinema Context,” TMG Journal for Media History 21, no. (2018), 106-126.

25. Kathy Charmaz, Constructing Grounded Theory (London: Thousand Oaks, 2014).

26. Linda Hantrais, “Contextualization in Cross-National Comparative Research,” International Journal Social Research Methodology 2, no. 2 (1999): 93-108, there 93.

27. Hantrais, "Contextualization,” 94.

28. Hantrais, "Comparative Research Methods."

29. Hantrais, “Contextualization,” 94.

30. Julia Brannen, “Mixed Methods Research: A Discussion Paper,” ESRC National Centre for Research Methods, Methods Review Paper (2005), 23.

31. Hantrais, "Comparative Research Methods.” 
32. Eva Etzioni-Halevy, “Comparing Semi-Corruption among Parliamentarians in Britain and Australia," in Comparative Methodology: Theory and Practice in International Social Research, ed. Else Øyen (London: Sage, 1990), 113-133, there 118.

33. Willemen, "For a Comparative Film Studies," 99.

34. Biltereyst and Meers, "New Cinema History,” 10.

35. Hantrais, “Contextualization,” 105.

36. Jennifer Mason, "Semistructured Interview," in The SAGE Encyclopedia of Social Science Research Methods, ed. Michael S. Lewis-Beck, Alan Bryman and Tim Futing Liao (London: Sage, 2004), https://dx.doi. org/10.4135/9781412950589.n909.

37. See Annette Kuhn, “Heterotopia, Heterochronia: Place and Time in Cinema Memory,” Screen 45, no.2 (2004): 106-114.

38. See Annette Kuhn, An Everyday Magic. Cinema and Cultural Memory (London: I.B. Tauris, 2000); Robert C. Allen, "Reimagining the History of the Experience of Cinema in Post-Moviegoing Age," Media International Australia 139, no.1 (2011): 80-87; Annette Kuhn, “Home Is Where We Start From," in Little Madnesses: Winnicott, Transitional Phenomena and Cultural Experience, ed. Annette Kuhn (London: I.B.Tauris, 2013), $53-64$.

39. See Karina Aveyard, “The Place of Cinema and Film in Contemporary Rural Australia," Participations 8, no. 2 (2011): 294-307; Daniel Biltereyst, “Audience as Palimpsest. Mapping Historical Film Audience Research,” presented at Researching Past Cinema Audiences: Archives, Memories and Methods conference (Aberystwyth University, UK, 2018).

40. Bornat, "Oral History and Remembering," 32.

41. Hantrais, "Comparative Research Methods."

42. Biltereyst and Meers, "New Cinema History,” 25.

43. Hantrais, "Comparative Research Methods."

44. Alessandro Portelli, "What makes Oral History Different," in The Oral History Reader, ed. Robert Perks and Alistair Thomson (London: Routledge, 1998), 63-74, there 67.

45. Henglien Lisa, "Cross-National Qualitative Research into the Long-Term Care of Older People: Some Reflections on Method and Methodology,” European Journal of Social Work 15, no. 4 (2012): 449-466. 


\section{Biographies}

Pierluigi Ercole is an Associate Professor in Film Studies at De Montfort University (Leicester, UK). Much of his research is grounded in audience and reception studies, transnational cinema and the diaspora and his work focuses, in particular, on Italian cinema, cinemagoing in Italy and Britain, Anglo-Italian film culture and the distribution and reception Italian films in the UK and Ireland. His publications include, among others, the edited volume Diviso in Due: Cesare Zavattini, Cinema e Culture Popolare (2002), the articles “Screening Fascism in the Free State," Historical Journal of Film, Radio and Television (2014); “The Greatest Film of the Fascist Era," Alphaville: Journal of Film and Screen Media (2013, special issue on ‘Reframing Cinema Histories’ co-edited with Gwenda Young). His work is also included in the edited collections Silent Italian Cinema: A Reader (2013) edited by G. Bertellini; Cinema, Audiences and Modernity: New Perspectives on European Cinema History (2011), edited by D. Biltereyst, R. Maltby and P. Meers.

Lies Van de Vijver is Co-Investigator and Project Manager of European Cinema Audiences (AHRC, 2018-2021), a comparative research into cinema audiences in seven European cities in the 1950s. She is affiliated with Ghent University and Oxford Brookes University. Her research has been published in Cultural Studies, European Journal of Cultural Studies, Participations, and in edited collections. She is editor of Mapping Movie Magazines (Palgrave, 2020) and is currently working on a book on cinema cul-ture in Ghent.

Daniela Treveri Gennari is Professor of Cinema Studies at Oxford Brookes University with a research interest in audiences, popular cinema, film exhibition and programming. Daniela has been leading the AHRC-funded project Italian Cinema Audiences and is currently leading the AHRCfunded project European Cinema Audiences: Entangled Histories and Shared Memories. Amongst her recent publica-tions: the edited volume Rural Cinema Exhibition and Audiences in a Global Context (Palgrave, 2018, with Catherine O’Rawe and Danielle Hipkins), the articles ““'It Existed Indeed... It Was All over the Papers': Memories of Film Censorship in 1950s Italy," Participations (2017, with Silvia Dibeltulo) and "Mapping Cinema Memories: Emotional Geographies of Cinema-going in Rome in the1950s,” Memories Studies (2017, with Catherine O’Rawe and Pierluigi Ercole). 


\section{TMG Journal for Media History}

Volume 23 No $(1 / 2) / 2020$

\section{DOI}

http://dx.doi.org/10.18146/tmg.586

\section{PUBLISHER}

Netherlands Institute for Sound and Vision

\section{COPYRIGHT}

Each article is copyrighted (c) by its author(s) and is published under license from the author(s). When a paper is accepted for publication, authors will be requested to agree with the Creative Commons Attribution 4.0 International License. 